\title{
Impact assessment of citizen science: state of the art and guiding principles for a consolidated approach
}

\author{
Uta Wehn ${ }^{1}$ ( $\cdot$ Mohammad Gharesifard ${ }^{1} \cdot$ Luigi Ceccaroni $^{2} \cdot$ Hannah Joyce $^{3} \cdot$ Raquel Ajates $^{4}\left(\mathbb{D} \cdot\right.$ Sasha Woods $^{2}$. \\ Ane Bilbao ${ }^{1} \cdot$ Stephen Parkinson ${ }^{2} \cdot$ Margaret Gold $^{5,6} \cdot$ Jonathan Wheatland $^{3}$
}

Received: 30 October 2020 / Accepted: 13 April 2021 / Published online: 12 May 2021

(c) The Author(s) 2021

\begin{abstract}
Over the past decade, citizen science has experienced growth and popularity as a scientific practice and as a new form of stakeholder engagement and public participation in science or in the generation of new knowledge. One of the key requirements for realising the potential of citizen science is evidence and demonstration of its impact and value. Yet the actual changes resulting from citizen science interventions are often assumed, ignored or speculated about. Based on a systematic review of 77 publications, combined with empirical insights from 10 past and ongoing projects in the field of citizen science, this paper presents guidelines for a consolidated Citizen Science Impact Assessment framework to help overcome the dispersion of approaches in assessing citizen science impacts; this comprehensive framework enhances the ease and consistency with which impacts can be captured, as well as the comparability of evolving results across projects. Our review is framed according to five distinct, yet interlinked, impact domains (society, economy, environment, science and technology, and governance). Existing citizen science impact assessment approaches provide assessment guidelines unevenly across the five impact domains, and with only a small number providing concrete indicator-level conceptualisations. The analysis of the results generates a number of salient insights which we combine in a set of guiding principles for a consolidated impact assessment framework for citizen science initiatives. These guiding principles pertain to the purpose of citizen science impact assessments, the conceptualisation of data collection methods and information sources, the distinction between relative versus absolute impact, the comparison of impact assessment results across citizen science projects, and the incremental refinement of the organising framework over time.
\end{abstract}

Keywords Citizen science $\cdot$ Impact assessment $\cdot$ Framework $\cdot$ Impact domains $\cdot$ Impact assessment approach $\cdot$ Measuring impact

Handledby Nora Fagerholm, University of Turku, Finland.

Uta Wehn

u.wehn@un-ihe.org

1 IHE Delft Institute of Water Education, Westvest 7, 2611 AX Delft, The Netherlands

2 Earthwatch Institute, Mayfield House, 256 Banbury Road, Oxford OX2 7DE, UK

3 River Restoration Centre, Cranfield University, Cranfield, Bedfordshire MK43 0AL, UK

4 University of Dundee, Nethergate, Dundee DD1 4HN, Scotland, UK

5 European Citizen Science Association, Invalidenstraße 43, 10115 Berlin, Germany

6 Universiteit Leiden, Niels Bohrweg 2, 2333 Leiden, CA, The Netherlands

\section{Introduction}

Over the past decade, citizen science has experienced growth and popularity-both as a scientific practice, and as an emerging form of stakeholder engagement and public participation in the generation of scientific knowledge-due to, among other things, the pervasive diffusion of information and communication technologies (Silvertown 2009; Bonney et al. 2009a, 2014). Its popularity as a novel form of stakeholder engagement and public participation in science stems from the increased realisation of its potential for jointly identifying and addressing common challenges of the twenty-first century (Fritz et al. 2019). Moreover, progress in addressing the challenges articulated in the UN Sustainable Development Goals (SDGs) can be monitored using citizen science for around $33 \%$ of the indicators of the SDG 
framework (Fraisl et al. 2020). Beyond the common notion of public participation in data collection for scientific purposes, a range of phenomena, activities and practices fall under the umbrella term 'citizen science' (ECSA 2020). We consider citizen science as a multifaceted phenomenon, consisting of collaborative data and knowledge generation among citizens, scientists and, in some case, decision makers, for a range of purposes, consisting of different dimensions (thematic, geographical, temporal, socio-political, scientific, technological and economic) which together influence the nature, remit, value and impact of any given citizen science initiative.

While the aspirations of citizen science are running high and the efforts to capture and report outputs, outcomes and impacts of citizen science are increasing, the actual changes resulting from citizen science interventions are often assumed, ignored or speculated about (Gharesifard et al. 2019b). Outputs refer to direct products of a citizen science initiative, while outcomes and impacts refer to short-term and long-term changes resulting from citizen science initiatives respectively. There is no blue-print for impact assessment of citizen science initiatives (Friedman 2008), due to the fact that the diversity of citizen science practices (e.g., various aims and thematic foci) and differing purposes of impact assessment (e.g., improving citizen science implementation, or reporting to funders), do not easily allow for a single methodology or approach to fit all. Moreover, limited resources (funds and expertise) and mismatches in the timing of impact assessments and impact manifestations quite often hinder a thorough assessment of the impacts of citizen science projects.

Previous literature review efforts have aimed to conceptualise, discuss and generate new insights on the impacts of citizen science. Jagosh et al. (2011) conducted a review of the participatory research literature which demonstrated that the diversity of research topics, intervention designs, and degrees of stakeholder involvement in the co-governance of research, and the complexity of outcomes render it difficult to evaluate such projects. Indeed, via a systematic review of 273 papers and 25 Community-Based Participatory Research (CBPR) projects, Sandoval et al. (2012) concluded that impacts and outcomes attributable to CBPR are often not (well) documented. Groulx et al. (2017) reviewed 145 studies to identify learning outcomes in citizen science projects relating to climate change and concluded that, despite initial discussions about such learning outcomes, evidence of these learning outcomes is not well documented. Based on an extensive literature review of 135 peer-reviewed publications, Fazey et al. (2014) concluded that evaluation of knowledge exchange is often an afterthought in interdisciplinary and multi-stakeholder environmental change research. Building on the literature from different fields of research, Hassenforder et al. (2016) and Gharesifard et al. (2019b) concluded that the identification of contextual variables is both important and challenging, and proposed conceptual frameworks that can help monitor and evaluate participatory processes and outcomes of citizen science. Following a structured review of citizen science project websites (327 in total), Phillips et al. $(2012,2014,2018)$ highlighted that, as the field of citizen science continues to grow, it is important to reflect on its impact, and on the type of questions that are being asked by practitioners and researchers for capturing impacts of citizen science initiatives. Moreover, existing review efforts are not limited to the review of scientific publications and insights from projects. For example, Granner et al. (2010) reviewed 2681 articles from 1764 newspapers and identified media content analysis as beneficial for evaluating citizen science initiatives.

Despite their diversity and expansiveness, existing literature reviews on the topic have had very specific thematic or methodological foci and, therefore, may have limited application for the wider field of citizen science. For example, the review by Sandoval et al. (2012) was conducted with a focus on CBPR partnerships and participation in health research and a pre-defined model of impact assessment (i.e., the CBPR Conceptual Logic Model). Other review efforts contain a bias towards bodies of literature from specific fields, such as the literature reviewed by Groulx et al. (2017), which includes publications in multi- and interdisciplinary journals, but only a limited number of publications from the social sciences. In addition, a limitation of these previous review efforts is their focus on a specific (or limited number of) impact domains, i.e., areas of change. Examples include Jagosh et al. (2011) and Hassenforder et al. (2016) which focus on governance impacts of participatory research projects; Phillips et al. (2012, 2014, 2018) which only focus on societal impacts; and Fazey et al. (2014), which is even more specific and only discusses the knowledge exchange outcomes in the context of research on multi-actor and interdisciplinary environmental change studies.

Collectively, the field of impact assessment within the 'science of citizen science' has made significant advances over the past two decades. However, if ongoing and future projects ignore the strengths and weaknesses of and lessons learned from previous impact assessment efforts, they run the risk of wasting resources, "reinventing the wheel" or maintaining the flaws and gaps of past impact assessment approaches. Impact assessment of previous citizen science projects, despite its limitations, offers various insights that can inform future impact assessment efforts by researchers and practitioners. This paper offers a consolidation of these insights into a coherent framework that can address and navigate the complexity of measuring the impacts of diverse citizen science initiatives.

The purpose of this research is therefore to generate guidelines for a consolidated Citizen Science Impact 
Assessment Framework (CSIAF) to enhance the ease and consistency with which impacts can be captured, as well as the comparability of evolving results across projects. We do so by combining a systematic literature review with empirical insights from ten past and ongoing projects in the field of citizen science. Specifically, in line with our view of citizen science as a multi-dimensional phenomenon, we frame our review according to five distinct, yet interlinked, impact domains:

- Society Impact on society and individuals as well as collective (societal) values, understanding, actions and wellbeing (including relationships).

- Economy Impact on the production and exchange of goods and services among economic agents; on entrepreneurial activity; economic benefits derived from data, e.g., for the public good or for the benefit of private sector actors.

- Environment Impact on the bio-chemical-physical environment, e.g., on the quality or quantity of specific natural resources or ecosystems.

- Science and technology Impact on the scientific process (method) as well as research more broadly; on the scientific system (institutions; science policy; incentive structures), scientific paradigms and resulting technological artefacts (e.g., sensors, apps, platforms) and standards.

- Governance Impact on the processes and institutions through which decisions are made, both informal and formal (e.g., public policy), and on relationships/partnerships, as well as the governance of data generated.

While the three interlinked domains of sustainable development (environment, society and economy) are well known and accepted, the context of citizen science warrants the focus on two additional domains, namely science and technology, and governance. The science and technology domain is considered due to citizen science's alignment with, and use of the scientific process and resulting (potential) implications for the scientific system, scientific paradigms and technological artefacts. An additional governance domain is considered owing to the links of citizen science processes and results to monitoring, (environmental) management and (public) decision-making processes. These impact domains arguably cut across many if not all of the Sustainable Development Goals (SDGs). Moreover, considering impacts in different domains is helpful for 'unpacking' them, drawing attention to and enabling analysis of distinctly different types of impacts, e.g., those to the physical environment [environment] as compared to those to institutional settings [governance]. Nevertheless, impacts in the different domains can be closely connected and may occur in sequence-interdependence even-rather than in parallel. For example, Wehn et al. (2020b) showed that case-specific changes in society (e.g., sense of place) and governance (e.g., improved support for participation in decision-making) are required before envisaged changes in the environment can be attained (e.g., improved air quality).

This paper is structured as follows: in the materials and methods section, we present the steps taken in the systematic literature and project review to select relevant papers and practices to capture insights. We present and discuss the resulting insights in the results and discussion section, and combine these into guiding principles for a citizen science impact assessment framework. In the conclusion section, we conclude the paper with reflections on future research and the limitations of our research.

\section{Material and methods}

The analysis of the state of the art in citizen science impact assessment approaches described in this paper is built on two main sources of information; (1) a systematic review of relevant academic literature about impact assessment in the field of citizen science and participatory research and (2) a small scale empirical research into current impact assessment practices in citizen science projects. Sections 2.1 and 2.2 provide details about the steps taken for the systematic literature search and review and Sect. 2.3 elaborates the methodology for collecting the empirical evidence.

\section{Selection of relevant literature}

The process of selecting relevant literature for this systematic review was iterative, based on the steps suggested by Moher et al. (2009) in the Preferred Reporting Items for Systematic Reviews and Meta-Analyses (PRISMA) approach, as illustrated in Fig. 1.

The purpose of this systematic literature search was to identify publications that propose or discuss impact assessment methods or approaches for evaluating citizen science initiatives, as well as publications that identify different impact domains of citizen science.

The starting point of this review was a list of 21 publications that were already known to the authors, mainly from a previous review of impact assessment methods in the Measuring Impact of Citizen Science (MICS) project (Wehn et al. 2020a). To complement this list, a further literature search was conducted in the Web of Science (WoS) and Wiley Online Library using relevant keywords. Keywords were compiled that referred to two distinct aspects of the literature; (1) the concept of citizen science and (2) impact assessment. Previous research has identified overlapping terms that refer to the concept of citizen science (Conrad and Hilchey 2011; Gharesifard et al. 2019a, b; Newman et al. 2011; Wehn and Almomani 2019; Whitelaw et al. 2003). 




Fig. 1 Summary of the steps for selecting relevant papers - modified from the PRISMA approach by Moher et al. (2009)

Building on these efforts, a set of keywords that refer to the concept of citizen science or closely related fields were identified (see Table 1). Similarly, a set of keywords was identified for the second aspect of the search, which relates to impact assessment terminology. The Boolean operators "AND" and "OR" were used to combine the search terms and the asterisk wildcard (*) was used to include different variations of each term.

The literature search in the WoS was conducted on 3 April 2020 by searching the 'Topic' of literature in the core collection of WoS that includes title, keywords and abstracts. This systematic search resulted in 8299 records. 
Table 1 Parameters used in the literature search

\begin{tabular}{|c|c|c|}
\hline \multirow{13}{*}{$\begin{array}{l}\text { Synonyms: combine } \\
\text { with OR }\end{array}$} & \multicolumn{2}{|l|}{ Aspects: combined with AND } \\
\hline & Aspect 1: the concept of citizen science & Aspect 2: impact assessment \\
\hline & Citizen science/citizen science & Impact* \\
\hline & Citizen observator* & Outcome* \\
\hline & Community-based monitoring /sensing/observation & Result* \\
\hline & Participatory monitoring/sensing/observation & Output* \\
\hline & Collaborative monitoring/sensing/observation & assess* \\
\hline & Volunteer monitoring/sensing/observation & Evaluat* \\
\hline & Citizen-based monitoring/sensing/observation & Measur* \\
\hline & Community-based monitoring/sensing/observation & Valid* \\
\hline & $\begin{array}{l}\text { Public participation in science/public participation in } \\
\text { research/public participation in scientific research }\end{array}$ & \\
\hline & Participatory research/participatory science & \\
\hline & science shop* & \\
\hline
\end{tabular}

The literature search in Wiley was conducted on 21 April 2020. Searching the 'Topic' of literature is not possible in Wiley; therefore, the literature in this repository was filtered based on the appearance of keywords in the abstracts. This search resulted in 1176 records. In addition to the literature mentioned above, 12 publications were identified by the authors via backward and forward snowballing (Wohlin 2014). This resulted in an initial list of 9508 publications, which were then screened for relevance. The eligibility criteria for inclusion was in-line with the purpose of the review and included (1) relevance for the field of citizen science and (2) focus on the topic of impact assessment. After removing duplicates and screening the topic, abstract and keyword, 92 publications were selected for full-text review. Next, the full texts of the publications in the shortlist were browsed to determine their relevance for inclusion in our full-text review, based on the subject matter addressed in the papers. During this process, 15 publications were discarded, resulting in a final list of 77 publications that are included in our synthesis. There were different reasons for the exclusion of records, for example their focus on technical details of citizen science initiatives instead of their impact, e.g., Brown et al. (2016), or a discussion on very specific impacts of citizen science (e.g., impact of community-based research on a specific health-related problem, as discussed in Corrigan and Shapiro (2010), or Naylor et al. (2002).

\section{Review process}

The full-text reviews were conducted in three phases to quality control the review process.

Phase 1 involved the setup of the approach, initial paper reviews and collation of information. Each co-author was assigned specific publications to read and review. During the review of each publication, the following information was recorded in a summary table:

- Scope and purpose of assessment Whether the publication proposes formative evaluation, summative evaluation or a comprehensive/holistic approach for capturing impacts (i.e., analysis of context, process and (evolving) impacts)

- Conceptual relevance: Insights of the publication regarding themes or indicator level.

- Thematic content Coverage of specific themes per domain (e.g., in the society domain: learning outcomes at individual or societal levels).

- Participatory evaluation: whether the method involves citizen scientists, not only in sharing their perceptions or collecting data on evolving impacts, but also devising relevant impact assessment indicators for their citizen science initiatives.

- Strengths and weaknesses: What are strengths and weaknesses of the approach for capturing impacts presented by the paper

In this phase, each co-author reviewed between six to ten publications. Marked versions of the reviewed publications (with highlighted sections related to the above bullet points) were saved for future analysis.

Phase 2 of the full-text review consisted of an internal peer-review process. During this phase, each author peerreviewed between six to ten publications that had already been reviewed by others in phase 1 . The peer-reviewers had access to the marked version of the publications (see phase 1). This step worked as a quality control mechanism to ensure that the reviews were thorough and that essential aspects or insights of the reviewed approaches had not 
Table 2 Overview of citizen science projects covered via interviews

\begin{tabular}{|c|c|c|c|c|c|}
\hline Project title & Website & Funding & Run time & $\begin{array}{l}\text { Dedicated } \\
\text { work pack- } \\
\text { age for IA? }\end{array}$ & $\begin{array}{l}\text { When impact was } \\
\text { measured }\end{array}$ \\
\hline I-mars.eu & http://www.i-mars.eu/ & $\begin{array}{l}\text { European Commission } \\
\text { (FP7) }\end{array}$ & Jan 2014-Mar 2017 & No & During the project \\
\hline Citclops & http://www.citclops.eu/ & $\begin{array}{l}\text { European Commission } \\
\text { (FP7) }\end{array}$ & Oct 2012-ongoing & No & During the project \\
\hline FreshWater Watch & $\begin{array}{l}\text { https://freshwaterwatch. } \\
\text { thewaterhub.org/ }\end{array}$ & Private funding & Nov 2012-ongoing & No & At the end \\
\hline Naturehood & https://naturehood.uk/ & $\begin{array}{l}\text { National Lottery Heritage } \\
\text { Fund }\end{array}$ & May 2019-ongoing & No & During the project \\
\hline D-NOSES & https://dnoses.eu/ & $\begin{array}{l}\text { European Commission } \\
(\mathrm{H} 2020)\end{array}$ & April 2018-Mar 2021 & $\begin{array}{l}\text { Yes (deliv- } \\
\text { erables } \\
\text { dedicated } \\
\text { to IA) }\end{array}$ & During the project \\
\hline Earth Challenge 2020 & $\begin{array}{l}\text { https://earthchallenge2 } \\
\text { 020.earthday.org/ }\end{array}$ & N/A & Apr 2020-Dec 2020 & No & At the end \\
\hline $\begin{array}{l}\text { Swedish Mass Experi- } \\
\text { ment } 2020\end{array}$ & $\begin{array}{l}\text { https://forskarfredag.se/ } \\
\text { researchers-night/mass- } \\
\text { experiments/ }\end{array}$ & $\begin{array}{l}\text { The Swedish Energy } \\
\text { Agency and Consu- } \\
\text { pedia }\end{array}$ & May 2020-Apr 2021 & No & During the project \\
\hline CitieS-Health & https://citieshealth.eu/ & $\begin{array}{l}\text { European Commission } \\
(\mathrm{H} 2020)\end{array}$ & Jan 2019-Dec 2021 & Yes & During the project \\
\hline Outfall Safari & $\begin{array}{l}\text { https://catchmentbaseda } \\
\text { pproach.org/learn/outfa } \\
\text { ll-safari-guide/ }\end{array}$ & $\begin{array}{l}\text { Thames Water and the } \\
\text { Environment Agency }\end{array}$ & May 2016-ongoing & No & During the project \\
\hline ACTION & https://actionproject.eu/ & $\begin{array}{l}\text { European Commission } \\
(\mathrm{H} 2020)\end{array}$ & Feb 2019-Jan 2022 & Yes & During the project \\
\hline
\end{tabular}

been missed, and to reduce subjective judgments about the reviewed impact assessment approaches and methodologies.

In phase 3 , the peer review results were cross-checked by the lead authors (the first and second author) who have expertise in both social and natural sciences, and any discrepancies between the initial and first peer review results were resolved via discussion among the lead authors.

The three-phased review ensured an unbiased and complete review of the 77 publications, therefore allowing a comprehensive review and discussion of the current state of citizen science impact assessments.

\section{Empirical research into current impact assessment practices of citizen science projects}

The second source of information for this study consists of empirical evidence obtained via dedicated, semi-structured interviews with the coordinators of the following ten citizen science projects (see Table 2). The projects were selected via convenience sampling, i.e., drawing on projects known to the authors. The interviews were carried out with project coordinators who were already closely connected to the MICS project or members of the MICS consortium including a member of the MICS advisory board, two project coordinators of a citizen science project from the MICS UK case study of the MICS project, and four projects led by members of staff at Earthwatch. None of the interviewed project coordinators from Earthwatch were involved in the MICS project. In addition, all the coordinators of the 'SwafS' projects ${ }^{1}$ which were active in January 2020 were also invited to interview and, of the ten coordinators approached, four agreed to be interviewed.

Specifically, 11 interviews (1 interview per project except for Outfall Safari which had 2 interviews) were held in the first quarter of 2020 to elicit the projects' current citizen science impact assessment approaches. Nine interviews were conducted by the co-authors from Earthwatch and the two interviews with Outfall Safari were done by the co-authors from the River Restoration Centre. From the 11 interviews, 4 were conducted face-to-face, 5 online and 2 via telephone. All responses to the questions were captured in form of notes taken during the interviews. The list of questions asked during the interviews is provided in the supplementary material. The results of these interviews were analysed using the MAXQDA software. The coding of the interview transcripts

\footnotetext{
1 SwafS (Science with and for Society) were a set of calls issued during 2018-2020 as part of the EU Horizon 2020 Framework Programme.
} 
was done deductively, based on the approach applied during the literature review (see Sect. 2.2). It served to identify, per project, the purpose of impact assessment activities and the methods and approaches currently used (including participatory approaches) that represent the 'scope and purpose of the assessment', impact domains of interest and impact indicators that relate to the 'conceptual relevance' and 'thematic content' of the approaches, as well as challenges encountered in assessing the impacts of their citizen science activities that can be linked to the 'strengths and weaknesses' of each approach.

This qualitative research was undertaken to provide the study with empirical evidence of current practice in the impact assessment of citizen science projects. As a complementary method to the systematic literature review, the qualitative research was undertaken from an analyticist situatedness perspective: the authors explicitly positioned themselves as peers of the interviewed citizen science practitioners and used the interviews to engage with them in a discussion about impact assessment in citizen science projects. The use of convenience sampling was a valid methodological approach for generating findings that provide indicative anecdotal evidence. While these findings have limited generalizability, they serve to illustrate the range of methods currently used for citizen science impact assessments as well as limitations of current practice. A limitation of the research is that a systematic sampling approach may have resulted in identifying additional impact domains. The validity of the generation and interpretation of the results was ensured through joint coding and analysis by the co-authors. Specifically, two teams from the co-authors coded the interviews and interpreted the results. Each team peer-reviewed the coding and interpretation of the other group. Then the two teams cross-checked the results of the peer-reviews and resolved discrepancies (regarding the coding of project proposal justification and education indicators; none regarding interpretation) via joint discussions with both teams.

\section{Results and discussion}

In the subsections below, we present the results of the systematic literature review and the findings from the empirical research into current impact assessment practices of citizen science projects. These are followed by a discussion of the combined insights which we present as a set of guiding principles for a consolidated CSIAF.

\section{Results of the systematic literature review}

Each of the reviewed publications considers one or more of the five impact domains, namely; Society, Economy, Environment, Science and Technology, and Governance (see
Fig. 2). The only exceptions were two publications which focus on generic impact assessment approaches instead of specific impact domains (Jacobs et al. 2010; Reed et al. 2018). The two publications with generic impact assessment approaches are not included in the subsequent domainspecific analysis. A detailed overview of the relevance of the reviewed publications per domain is presented in Table in supplementary material. The majority of the reviewed approaches focus on measuring impacts in 1 or 2 domains (32 and 19, respectively); only 2 out of the 77 reviewed publications referred to all 5 domains (Gharesifard et al. 2019a, b).

As is evident from Fig. 3, the reviewed literature addresses the five impact domains at distinctly different levels of intensity, with the largest number of publications $(n=65)$ in the society impact domain and the lowest in the economy domain $(n=12)$.

The review also captured whether a publication focused on measuring impacts at different levels of abstraction, namely thematic level insights or with concrete indicators. Insights at the thematic level here refer to identification of different themes (or areas of application) within each domain. For example, Ballard et al. (2017) discuss sciencerelated outcomes in biodiversity research and Cook et al.



Fig. 2 Number of domains addressed per publication $(n=77)$. (Asterisk) N/A refers to publications that do not define any specific domains

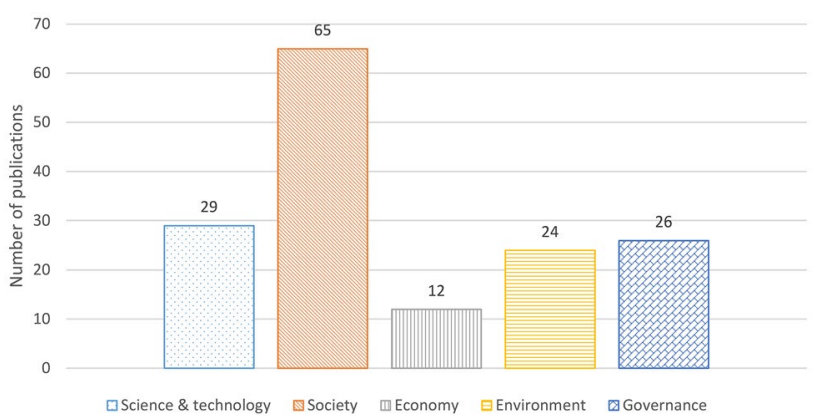

Fig. 3 Relevant publications identified per domain $(n=77)$. (Asterisk) Some publications contribute insights to more than one domain 
(2017) focus on science-related outcomes in the theme of participatory health research, but neither of them provide indicators for measuring these. In contrast, Jordan et al. (2012) provide specific indicators for measuring sciencerelated results of citizen science projects within the theme of ecological monitoring, for example, short or longer term changes in understanding of natural systems or number of peer-reviewed publications. As illustrated in Fig. 4, except for the two generic publications (see Fig. 2), all other publications in each domain provide insights at the thematic level, in contrast, a far smaller number of publications in the same domain offer insights at the indicator level.

The largest share of the reviewed publications did not include evidence and supporting material of measured baselines situation, outcomes and/or impacts (e.g., a supplementary material). The 12 notable exceptions (out of 77 papers in total) are Bremer et al. (2019), Gharesifard et al. (2019a), Grudens-Schuck and Sirajuddin (2019), Guldberg et al. (2019), Hassenforder et al. (2016), Haywood (2015), Hobbs and White (2016), Khodyakov et al. (2013), Merenlender et al. (2016), Trimble and Lazaro (2014), Wehn et al. (2019b, 2020a, b, c).

In the society domain, there is a general distinction in the reviewed literature between (1) individual and collective level outcomes and (2) changes in knowledge, attitude and behaviour. One key theme relates to (individual and social) learning outcomes. Other salient themes relate to changes in relationships and partnerships among societal actors, community dynamics (including capacity, wellbeing and livelihoods) and changes in the understanding of and attitudes towards science, which provide cross-cutting links to the science domain. In the society domain, 31 publications provided specific indicators (Fig. 4). Examples include:

- Indicators of community participation (Butterfoss 2006, p. 331):

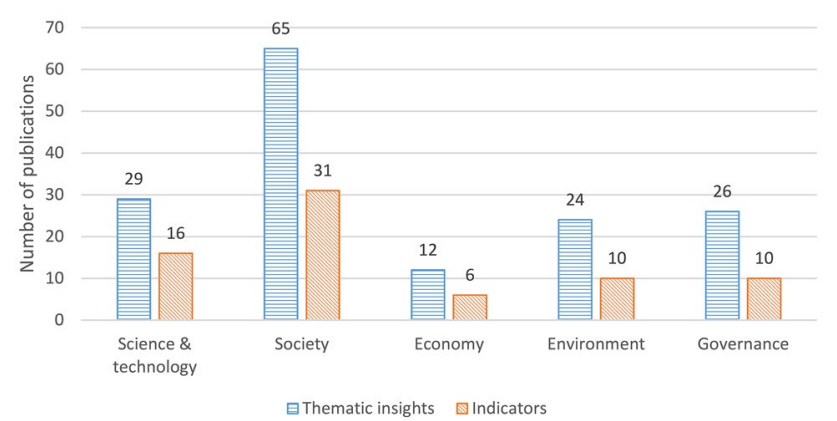

Fig. 4 Publications offering insights at thematic and indicator level per domain $(n=77)$
- Indicators of science inquiry skills of participants in citizen science initiatives (Philipps et al. 2018; p. 9):

o "asking and answering questions

o showing increased confidence in being able to collect data

o collecting data

o submitting data

o developing and using models

o planning and carrying out investigations

o reasoning about, analysing, and interpreting data

o constructing explanations

o communicating information

o using evidence in argumentation"

The themes and indicators in the science and technology domain focus on largely quantifiable outputs of the scientific process (e.g., data, publications and citations). Some approaches (Kieslinger et al. 2017; 2018; Chandler et al. 2017) capture changes to the scientific process via public participation and community engagement, changes in community-academia relations and enhancements of the scientific knowledge base 16 publications contributing to the science and technology domain provide indicators (Fig. 4). For example, Kieslinger et al. (2018; pp. 88-92) propose indicators in the form of closed questions, such as

o "Does the project demonstrate an appropriate publication strategy?

o Are citizen scientists recognised in publications?

o Did the project generate new research questions, projects or proposals?

o Did the project contribute to any institutional or structural changes?

o Does the project ease access to traditional and local knowledge resources?

o Does the project contribute to a better understanding of science in society?"

Chandler et al. (2017; p. 172) suggests indicators such as the number of

o "people and person hours dedicated to collecting scientific data,

o popular publications and outreach events" 
The themes in the environmental domain focus on the status of environmental resources, e.g., resulting from conservation efforts, ecosystem functions, services and resilience, as well as impacts of environmental status on human health and livelihoods (cutting across to the society domain) and outcomes for agricultural productivity (cutting across to the economy domain). Indicators were identified in ten of the publications relating to the environment domain, such as

o "improved conservation action leading to better ecosystem function, ecosystem services and resilience" (Pocock et al. 2018; p. 278)

o "enhanced natural habitats and ecosystem services" (Chandler et al. 2017; p. 172).

The themes in the economy domain cover demand and supply aspects of citizen science, including the generation of economic entrepreneurial activities. While the total number of contributions in this domain is already small $(n=12)$, out of these, only six publications actually provide concrete indicators. Indicators on the demand side include

o "number of jobs created" (Jordan et al. 2012; p. 308)

o "added value of citizen science data

o change in company growth

o international trade and investment" (Wehn et al. 2017; 36).

The contributions in the governance domain cover a wide range of themes, including the policy cycle, as well as actual changes in policy, multi-level interactions among actors and their power dynamics, communication, relationships and trust. Most contributions highlight relevant themes and only ten publications provide specific indicators. For example,

o "contributions to management plans and policy" (Chandler et al. 2017; p. 172)

o "stakeholder interactions in decision-making processes (e.g., data provision, expressing preferences, deliberation and negotiation, etc.)" (Wehn et al. 2017; p. 34)

o "change in the level of authority and power off each stakeholder" (Wehn et al. 2017; p. 35)

Along with the definition of indicators, the reviewed literature describes guidelines on how to collect evidence of impact in each domain. The analysis of the methodological approaches used or referred to reveals that a mixed methods approach (qualitative and quantitative) is by far the most commonly proposed (discussed in $>70 \%$ of publications reviewed) approach for capturing impacts of citizen science in the different domains (Fig. 5). The highest percentage of quantitative impact assessment approaches were recorded in the science and technology, and the society domains (Fig. 5); these were the domains with the highest number of papers with specific indicators (Fig. 4). This could be because these two impact domains are frequently assessed in citizen science projects. However, overall, there is a low percentage $(<8 \%)$ of quantitative methods used in all five domains (Fig. 5); this could be because of the difficulties with quantifying the impacts of citizen science. The methods used include (and often combine) observations, (semi)structured interviews, questionnaire-based surveys, generating data from document analysis via checklists, gathering data from a variety of stakeholders (including non-participants) to capture the diversity of views about the baseline situation (even in retrospect) and evolving outcomes and impacts at multiple times throughout the project.

The review of 77 impact assessment publications highlights that currently there are no standardised guidelines for assessing citizen science impact, and there is an imbalance in the domains in which citizen science impact is assessed (only 2 out of 77 publications reviewed covered all impact domains). Therefore, there is a need to build on the insights from existing impact assessments and develop a guiding framework that is able to address and navigate the complexity of measuring the impacts of citizen science across all five impact domains.

\section{Empirical evidence of current impact assessment practices}

The results of the empirical enquiry among citizen science project coordinators are summarised in Table 3. The Code System column presents the identified insights from qualitative analysis of the interviews. These insights are categorized in five groups, namely; purpose of impact assessment, method of impact assessment, impact indicators for, impact domains and challenges of impact assessment. The Coded Segments column shows the number of times that the coded insights appeared in all 11 interviews, while the

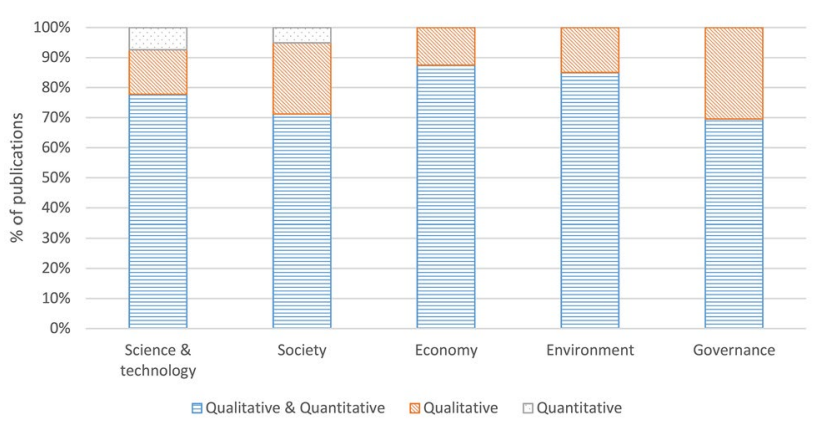

Fig. 5 Methodological approach used for capturing citizen science impacts (per domain) $(n=77)$ 
Table 3 Coded results of interviews with citizen science project coordinators (highlighted rows indicate the aspects with the highest frequency of occurrence)

\begin{tabular}{|c|c|c|}
\hline Code System & \multirow{2}{*}{\begin{tabular}{r|} 
Coded Segments \\
158
\end{tabular}} & \multirow{2}{*}{$\begin{array}{r}\text { Number of interviews } \\
11\end{array}$} \\
\hline & & \\
\hline \multicolumn{3}{|l|}{ Purpose of impact assessment } \\
\hline Project proposal justification & 6 & 6 \\
\hline Learning purposes & 5 & 5 \\
\hline Advertising, promotion \& outreach & 3 & 3 \\
\hline Accounting/Reporting purposes & 10 & 8 \\
\hline Project evaluation and improvement & 2 & 1 \\
\hline \multicolumn{3}{|l|}{ Methods of impact assessment } \\
\hline Ex ante impact assessment & 3 & 3 \\
\hline Logic framework (Impact Journey) & 3 & 1 \\
\hline Impact stories & 5 & 5 \\
\hline Impact value chain & 1 & 1 \\
\hline Cost/benefit analysis & 1 & 1 \\
\hline Surveys, interviews \& feedback forms & 12 & 9 \\
\hline Statistics on tool usage & 8 & 5 \\
\hline \multicolumn{3}{|l|}{ Impact indicators } \\
\hline Data points collected & 9 & 8 \\
\hline Data quality & 3 & 3 \\
\hline Citizens involved & 9 & 6 \\
\hline Attitudes changed & 7 & 5 \\
\hline Actions taken & 2 & 2 \\
\hline Policies changed & 2 & 2 \\
\hline Papers published & 2 & 2 \\
\hline Awareness raised & 5 & 4 \\
\hline Media attention & 1 & 1 \\
\hline \multicolumn{3}{|l|}{ Impact Domains } \\
\hline Society & 7 & 5 \\
\hline Science \& Technology & 7 & 6 \\
\hline Economy & 3 & 3 \\
\hline Environment & 5 & 5 \\
\hline Governance & 5 & 4 \\
\hline \multicolumn{3}{|l|}{ Challenges for impact assessment } \\
\hline Timeline: project activities vs. impact manifestation & 4 & 3 \\
\hline Collection of impact data & 5 & 4 \\
\hline Project priorities & 5 & 3 \\
\hline Competence & 2 & 2 \\
\hline Availability of resources & 1 & 1 \\
\hline
\end{tabular}

Note: 'participatory evaluation' refers to situations whereby citizens were involved beyond sharing their perceptions or collecting data, by e.g. devising relevant impact assessment indicators. Such incidents were coded in the category 'impact indicators' and sub-code 'citizens involved'.

'Number of Interviews' corresponds with the number of project coordinators who referred to each coded insight in their responses. The reasons (or purposes) for citizen science impact assessment varied from justifying the project during the proposal stage; increasing levels of insight generation later in the project, whether for personal/internal purposes 
(e.g., learning); helping promote the citizen science initiative; accounting or reporting (e.g., to funders or financial accountants); or even for improving project activities and the attainment of envisaged results and impacts via adaptive management (project evaluation and improvement). Accounting/reporting was the dominant reason (coded ten times across eight of the interviews) for measuring impact in the different citizen science projects (Table 3 ).

The interview results indicate a range of methods for collecting evidence of impacts are used, differing in terms of timing of the methods' application in different project stages (e.g., ex-ante impact assessment before either the start of the project or the hands-on citizen science activities on the ground), as well as in terms of structuring and capturing impacts (e.g., capturing narrative impact stories vs structured surveys or interviews with a range of stakeholders) and focus of analysis (e.g., focus on actors' perspectives, or analysing the usage of citizen science tools). Surveys, interviews and feedback forms were the most commonly mentioned form of impact assessment mentioned 12 times across nine of the interviews (Table 3 ).

The impact indicators mentioned by the interviewed citizen science practitioners reflect some blurring of definitions or distinctions of terminology, e.g., referring to number of data points collected (arguably these are outputs, not impacts). Nevertheless, the responses indicate the broad range of impact indicators in use, which include not only cognitive changes in awareness of the topic that is the focus of a citizen science initiative, but also changes in attitudes, actions and policy.

Notably, the five impact domains were confirmed as relevant, albeit to differing degrees by the respective respondents. No additional domains were suggested. Similar to the 77 publications reviewed, the impact domains of science and technology and society, had the highest coding and were mentioned in $>45 \%$ of the interviews with practitioners. Finally, a number of challenges for undertaking impact assessments of their citizen science projects were identified, relating to the well-known dilemma of misalignment in terms of timing of funded project activities versus the (longer term) manifestation of envisaged (and observable) impacts; difficulties associated with collecting data about impacts; project priorities limiting the attention to impact assessment activities; lack of competencies to undertake sound impact assessment among project partners; and unavailability of resources.

\section{Discussion}

The analysis of the results presented in Sect. 3.1-especially the strengths, weaknesses and lessons learned from the application of citizen science impact assessment approaches-as well as the empirical evidence from citizen science projects presented in Sect. 3.2, generate a number of salient insights which we combine here into six guiding principles for a consolidated Citizen Science Impact Assessment Framework (CSIAF). Specifically, these guiding principles refer to the purpose of assessing impact in the context of citizen science, the conceptualisation of data collection methods and information sources for impact assessment, the distinction between relative impact versus absolute impact, the comparison of impact assessment results across citizen science projects, and the incremental enhancement of the organising framework over time. Below, we list the six principles to inform a consolidated CSIAF which, we hope, can serve citizen science practitioners (e.g., project coordinators, community managers) and impact researchers alike.

Putting these principles into practice to compose a consolidated CSIAF will involve the careful comparison, alignment and (if appropriate) combination of relevant indicators per domain and theme, along with the selection of data collection methods to capture evidence of (emerging) impacts. The framework will be implemented as an online resource and tool via a dedicated effort of the MICS project ${ }^{2}$ and rolled out to citizen science initiatives in Europe and globally during 2021.

\section{Principle 1: Acknowledging a variety of purposes of citizen science impact assessment}

The reasons for the impact assessment of citizen science projects differ from impact reporting to learning for improved (future) implementation and even ex-ante impact assessment to substantiate proposal and grant applications and capture baselines. Thus, the CSIAF needs to be able to accommodate a range of reasons, purposes and timing of undertaking impact assessment within citizen science projects. This requires projects to consider both, process-related as well as results-related indicators (Haywood and Besley 2013; Ravn et al. 2016; Wehn et al. 2020c) $)^{3}$. Benchmarks and feedback on the extent to which and how envisaged results are and can be achieved are also recommended and can feed into the adaptive management of projects. At the moment, although some of the 77 reviewed publications highlight the role of evaluation in adaptive project management (e.g., Kieslinger et al. 2017; Wehn et al. 2017, 2020a, b, c), most do not provide explicit examples of projects that have changed or

\footnotetext{
${ }^{2}$ Measuring the impacts of Citizen Science (MICS), H2020 (20192021), www.mics.tools

${ }^{3}$ For example, as process indicators, the number and categories of stakeholders engaged in a citizen science project (Butterfoss (2006) and, as results indicators, number of papers published, citations and grants received; size and quality of citizen science databases (Kieslinger et al. 2017; 2018). Nevertheless, some indicators may be used to measure both, process and results, depending on the purpose, focus and the timing of the assessment (Blackstock et al., 2007).
} 
adjusted their strategies based on assessing impacts during the lifetime of the project. ${ }^{4}$

\section{Principle 2: Non-linear conceptualisation of impact journeys to overcome impact silos}

The intervention logic (also known as results chain or logical framework approach) is behind many impact assessment efforts of public interventions and-in particular-the assessment of research activities, namely the MoRRI framework (Monitoring Responsible Research \& Innovation RRI) (Ravn et al. 2016) as well as evaluations of citizen science efforts (e.g., DITOS Consortium 2016). The definitional system of the logic framework in terms of outputs, outcomes and impacts provides useful distinctions for the different results emerging before eventual impact is achieved. Nevertheless, its inherent linear conceptualisation and generic set definitions are limiting, offering too little guidance on the changes related to citizen science. This can result, among others, in 'impact silos', i.e., lack of awareness of other relevant types of impacts.

Moreover, evidence from citizen science impact assessments has shown that impact journeys 'zigzag' across multiple domains, i.e., there are dependencies in terms of the sequence of distinct outcomes, such as social and institutional changes before the realisation of environmental improvements (Wehn et al. 2020b; Wood et al. 2020; Pólvora and Nascimento (2017).

A comprehensive CSIAF therefore needs to provide relevant impact domains as well as sufficient flexibility in the selection of relevant impact domains and respective outcomes. Our systematic review of existing citizen science impact assessment efforts confirmed the domains of society, economy, environment, governance, and science \& technology.

Citizen science practitioners need to be able to plan and trace impact pathways in and across (a subset of) these domains. To do so, not only are sound distinctions between outputs, outcomes and impacts in each domain essential (Friedman 2008; Bonney et al. 2009b; Koontz and Thomas 2012), but also, causal relations between intermediary outcomes and impacts within a given domain, and between outcomes in different domains must be identifiable and traceable. Moreover, citizen science already is contributing to monitoring five SDG indicators and could contribute to 76 indicators, together amounting to 33\% (Fraisl et al. 2020),

\footnotetext{
4 An example of strategy changes is the response to the baseline analysis of the Ground Truth 2.0 citizen observatory in the Netherlands, which clarified the formal role as well as the ambitions of staff of the water authority for the observatory (Wehn et al. 2019a). This triggered substantive changes in the stakeholder engagement strategy and resulted in more intense involvement of the water authority staff (Wehn et al. 2020b).
}

providing not only data but a means for stimulating citizen action and informing and/or changing policy for SDG implementation. Therefore, it needs to be possible to select and adjust over time which SDGs the citizen science project intends to monitor and actually contributes to, as a project may pivot towards a different or additional goal.

\section{Principle 3: Adopting comprehensive impact assessment data collection methods and information sources}

Reliable impact assessment of citizen science projects involves a range of data collection methods and sources and ideally captures them not only from participants (i.e., citizen scientists) but also other relevant stakeholders and beneficiaries (Wehn et al. 2017; Guldberg et al. 2019) who can provide evidence of a range of (evolving) impacts. Some recent citizen science and citizen observatory projects have attempted more comprehensive reviews (e.g., Woods et al. 2019; Wehn et al. 2017, 2019b, 2020b). For example, Wehn et al. (2017) proposed and repeatedly applied (Wehn et al. 2019b, 2020a, b, c) a results-based approach that was complemented with relevant theoretical concepts ${ }^{5}$ and carefully designed data collection instruments and selected methods, ${ }^{6}$ to capture the particular social, institutional and economic changes linked to the implementation of six citizen observatories that ultimately aim for improvements in the environment. This combination of project monitoring, validation and impact assessment provided a comprehensive feedback tool to inform improvements to the final citizen observatories and innovate specific aspects of the initiatives and technological tools (apps, online platforms). The way in which project partners, stakeholders and beneficiaries provide evidence needs to allow and guide them within a wide range of suitable methods of impact assessment data collection, but without being prescriptive (Phillips et al. 2012,2014,2018) to"...standardise good practice in evaluation rather than use standard evaluation methods and indicators" (p. 143) without consideration for validity of methods to cover wide range of citizen science practices and impacts (Reed et al. 2018). Such guidance towards good practice needs to encourage the provision of evidence of impacts whenever possible, including, for example, in supplementary material of papers reporting on citizen science impacts.

\footnotetext{
5 E.g., community resilience (Norris et al. 2008), participation paradigms, power dynamics among stakeholders and existing institutions (Fung 2006; Wehn et al, 2015) and economic demand and supply indicators (European Commission 2015).

${ }^{6}$ Appropriate methods for collecting the respective data consisted of interviews, survey, social media analysis, content and analytics from the citizen observatory online platforms, observation, focus groups and the use of secondary data sources (e.g., official statistics).
} 
Moreover, data collection for impact assessment of citizen science activities under the CSIAF should allow its users (i.e., citizen science practitioners and impact researchers) to 'practice what we preach' by involving citizen scientists in the collection of evidence about impacts as they emerge over time, gathering measurements not only of 'scientific' indicators but also of community-defined successes (Hermans et al. 2011; Haywood 2015; Graef et al. 2018; Constant and Roberts 2017; Tricket and Beehler 2017; Arora et al. 2015; Jacobs et al. 2010) such as Community Level Indicators (Coulson et al. 2018; Woods et al. 2019, 2020).

Citizen science projects have different types and levels of resources (financial resources, time, networks and qualified staff) at their disposal for their impact assessment efforts which can affect the extent of their impact assessment efforts and hence the type and range of evidence that they can capture. The CSIAF should therefore provide sufficient and appropriate guidance, as well as links to relevant resources that it can be applied in both a 'light-touch' and more comprehensive manner.

\section{Principle 4: Moving beyond absolute impact}

The limitations of sticking to absolute and fixed measures of impact (typically quantified) are becoming increasingly evident, including in the field of citizen science. For example, Cox et al. (2015) acknowledge bias caused by quantitative comparison of impacts of longer running projects against those that have been running for a short period of time. Sound impact assessment needs to measure impact relative to the context and the goals and objectives of citizen science projects (Reed et al. 2018; Gharesifard et al. 2019b). The CSIAF needs to provide the means to enter and measure progress against project-specific objectives and to take context into account, including geographical context, socio-economic setting, available resources such as time, financial, staff, etc., and by providing comparisons to a different citizen science project, a non-citizen science project, or a lack of project.

\section{Principle 5: Fostering comparison of impact assessment results across citizen science projects}

As we argued from the outset, the diversity of citizen science projects in terms of thematic issues addressed, stakeholders involved, and extent and type of impact assessment undertaken, make it challenging to compare results across projects (Cargo and Mercer 2008; Hassenforder et al. 2016; DITOs Consortium 2016; Kieslinger et al. 2017; Wiggins et al. 2018), or to other frameworks such as the Sustainable Development Goals (Fraisl et al. 2020). Similar to current efforts to build in interoperability across data systems and platforms of citizen science projects (Bowser 2017; Masó and Fritz 2019; Masó and Wehn 2020), cross-comparison of impacts and data impacts would be a beneficial development for citizen science. A comprehensive CSIAF can enable comparability of impact assessment results that are based on different methods and information sources using consistent overarching categories of definitions (Phillips et al. 2012; Reed et al. 2018; Gresle et al. 2019). This could be done, for example, by capturing impact assessment results from different projects via a single online tool (e.g., questionnaire) (Gresle et al. 2019) based on the CSIAF and, during the visualisation of individual and compared results, by distinguishing validity levels (e.g., via a color scheme) according to the range of underlying data sources. This can serve to generate both, project-specific as well as aggregated results.

\section{Principle 6: Cumulative enhancement of the framework over time}

The collective advancement of impact assessment theory and practice in the field of citizen science relies on reflection and cumulative additions, based on insights across projects and methods. To remain relevant over time and serve the citizen science community, the impact assessment needs to be built on collective and cumulatively evolving intelligence, based on additional inputs and definitions by researchers and practitioners as well as more structured reflection and quality control (peer review) to check whether appropriate items, definitions and methods are being used.

A tiered level of indicators (similar to the SDG Tier 1-2 and 3 system of indicators ${ }^{7}$ ) may be used to indicate the maturity level or peer review status of new indicators that are under review. A similar system may need to be set up and maintained for curation of the CSIAF. Communities of Practice (CoPs) such as the WeObserve CoPs, and related fora such as Working Groups of the European Citizen Science Association ${ }^{8}$, can offer the continuity and space for practitioners to reflect on, discuss and refine CSIAFs. For example, the WeObserve project ${ }^{9}$ launched four Communities of Practice as a key mechanism for consolidating the

\footnotetext{
7 Tier 1 and 2 : indicator is well conceptualized and has an internationally agreed-upon methodology vs. Tier 3: internationally established standards and methodologies are not yet available; however, standards and methodologies are under development.

${ }^{8}$ ECSA Working Groups cover strategic work of the association by means of organising ECSA members around specific topics. There is no ECSA WG dedicated to impact assessment but relevant WGs touching upon impact assessment in citizen science include, among others, the empowerment, inclusiveness and equity WG; policy, strategy, governance and partnerships WG; and sharing best practice and building capacity WG.

9 weobserve.eu, H2020 (2017-2021).
} 
knowledge within as well as beyond the WeObserve consortium. These CoPs serve as a vehicle for sharing information and creating new knowledge on selected key thematic topics related to citizen science and include one CoP dedicated to capturing the impact and value of citizen science. These fora have contributed to strengthening the knowledge base about citizen science in general and on citizen science impact assessment in particular.

\section{Conclusions}

This paper has presented a systematic review of impact assessment methods for citizen science, the resulting insights of which provide guidance for a consolidated citizen science impact assessment framework. The ambition of such a consolidated framework is to overcome the dispersion of approaches and gaps in assessing the diversity of impacts that citizen science projects can generate.

The insights generated by this study have been combined into six guiding principles for a consolidated citizen science impact assessment framework, namely (1) acknowledging that there are a variety of purposes for citizen science impact assessment; (2) conceptualising non-linear of impact journeys to overcome impact silos; (3) adopting comprehensive impact assessment data collection methods and information sources (qualitative as well as quantitative); (4) moving beyond absolute impact to include relative impact; (5) fostering comparison of impact assessment results across citizen science projects; and (6) cumulative enhancing the framework over time.

This study has shown that a key characteristic of such a framework is not only its conceptual grounding in the latest insights, but its flexibility in terms of the purpose for which citizen science projects undertake impact assessment activities and the resources (means) that they have at their disposal to capture evidence of emerging impacts. Providing flexibility for both aspects will maximise the usability of the proposed consolidated CSIAF- and therefore the impact that the CSIAF itself will have among the community of citizen science practitioners.

The publications and interview data reviewed in this study stem from diverse scientific fields and epistemological approaches, incorporating distinct perspectives and framings not only of impact assessment, but also citizen science. This diversity goes hand in hand with the use of varied and comprehensive data collection methods to capture evidence of (emerging) impacts. A key step in the compilation of the framework must therefore be the careful comparison, alignment and (if appropriate) combination of relevant indicators per domain and theme. Also, many citizen science projects may have difficulties to generate an empirically based baseline situation (ex-ante) with respect to the initial stage of knowledge, understanding, attitudes and behaviour of key stakeholders and especially citizen scientists whom they aim to involve. The framework, therefore, needs to provide guidance on how to simulate this, e.g., by drawing on comparisons between participants and non-participants using existing data sources (government reports) as well as innovative data sources (e.g., social media) and analytical techniques (social media mining) and integrating estimates of past projects. These latter will become increasingly feasible with the implementation of the CSIAF framework as an online resource and tool by the MICS project, availing reference data from past projects.

This paper has contributed to current efforts in the citizen science community to enhance the ease and consistency with which impacts of projects, large or small, can be captured, as well as the comparability of evolving results across initiatives. Achieving the full potential of citizen science in whatever form it is practiced, requires, among other factors, evidence and demonstration of its outputs, outcomes and impact to highlight its potential for bringing about change and engagement.

Supplementary Information The online version contains supplementary material available at https://doi.org/10.1007/s11625-021-00959-2.

Acknowledgements This research has received funding from the EU Horizon 2020 research and innovation programme under projects MICS - Measuring Impact of Citizen Science (824711) and WeObserve (776740).

Open Access This article is licensed under a Creative Commons Attribution 4.0 International License, which permits use, sharing, adaptation, distribution and reproduction in any medium or format, as long as you give appropriate credit to the original author(s) and the source, provide a link to the Creative Commons licence, and indicate if changes were made. The images or other third party material in this article are included in the article's Creative Commons licence, unless indicated otherwise in a credit line to the material. If material is not included in the article's Creative Commons licence and your intended use is not permitted by statutory regulation or exceeds the permitted use, you will need to obtain permission directly from the copyright holder. To view a copy of this licence, visit http://creativecommons.org/licenses/by/4.0/.

\section{References}

Arora PG, Krumholz LS, Guerra T, Leff SS (2015) Measuring community-based participatory research partnerships: the initial development of an assessment instrument. Prog Commun Health Partnersh Res Educ Action 9(4):549-560. https://doi.org/10.1353/ cpr.2015.0077

Ballard HL, Robinson LD, Young AN, Pauly GB, Higgins LM, Johnson RF, Tweddle JC (2017) Contributions to conservation outcomes by natural history museum-led citizen science: examining evidence and next steps. Biol Conserv 208:87-97. https://doi.org/ 10.1016/j.biocon.2016.08.040

Blackstock KL, Kelly GJ, Horsey BL (2007) Developing and applying a framework to evaluate participatory research for sustainability. 
Ecol Econ 60(4):726-742. https://doi.org/10.1016/j.ecolecon. 2006.05.014

Bonney R, Ballard H, Jordan R, McCallie E, Phillips T, Shirk J, Wilderman CC (2009a) Public participation in scientific research: defining the field and assessing its potential for informal science education. A CAISE Inquiry Group Report, Center for Advance and Informal Science Education (CAISE), Washingtong DC

Bonney R, Cooper C, Dickinson J, Kelling S, Phillips T, Rosenberg K, Shirk J (2009b) Citizen science: a developing tool for expanding science knowledge and scientific literacy. Bioscience 59:977984. https://doi.org/10.1525/bio.2009.59.11.9

Bonney R, Shirk J, Phillips T, Wiggins A, Ballard H, Miller-Rushing A, Parrish J (2014) Next steps for citizen science. Science (New York, N. Y.) 343:1436-1437. https://doi.org/10.1126/science. 1251554

Bonney R, Phillips T, Ballard H, Enck J (2015) Can citizen science enhance public understanding of science? Public Underst Sci (Bristol, England). https://doi.org/10.1177/0963662515607406

Bowser A (2017) Standardizing citizen science? Proc TDWG 1:e21123. https://doi.org/10.3897/tdwgproceedings.1.21123

Bremer S, Haque M, Aziz MS, Kvamme S (2019) 'My new routine': assessing the impact of citizen science on climate adaptation in Bangladesh. Environ Sci Policy. https://doi.org/10.1016/j.envsci. 2018.12.029

Brossard D, Lewenstein B, Bonney R (2005) Scientific knowledge and attitude change: the impact of a citizen science project. Int J Sci Educ 27:1099-1121. https://doi.org/10.1080/0950069050 0069483

Brown A, Franken P, Bonner S, Dolezal N, Moross J (2016) Safecast: successful citizen science for radiation measurement and communication after Fukushima. J Radiol Prot 36(2):S82-S101. https://doi.org/10.1088/0952-4746/36/2/s82

Butterfoss F (2006) Process evaluation for community participation. Annu Rev Public Health 27:323-340. https://doi.org/10.1146/ annurev.publhealth.27.021405.102207

Cargo M, Mercer SL (2008) The value and challenges of participatory research: strengthening its practice. Annu Rev Public Health 29:325-350

Chandler M, Rullman S, Cousins J, Esmail N, Begin E, Venicx G, Studer M (2017) Contributions to publications and management plans from 7 years of citizen science: use of a novel evaluation tool on Earthwatch-supported projects. Biol Conserv 208:163173. https://doi.org/10.1016/j.biocon.2016.09.024

Chase S, Levine A (2016) A framework for evaluating and designing citizen science programs for natural resources monitoring: resource-based framework for citizen science. Conserv Biol. https://doi.org/10.1111/cobi.12697

Conrad CC, Hilchey KG (2011) A review of citizen science and community-based environmental monitoring: issues and opportunities. Environ Monit Assess 176(1-4):273-291

Constant N, Roberts L (2017) Narratives as a mode of research evaluation in citizen science: understanding broader science communication impacts. J Sci Commun 16(4):A03. https://doi.org/10. 22323/2.16040203

Cook T, Boote J, Buckley N, Vougioukalou S, Wright M (2017) Accessing participatory research impact and legacy: developing the evidence base for participatory approaches in health research. Educ Action Res 25(4):473-488. https://doi.org/10.1080/09650 792.2017.1326964

Corrigan PW, Shapiro JR (2010) Measuring the impact of programs that challenge the public stigma of mental illness. Clin Psychol Rev 30(8):907-922. https://doi.org/10.1016/j.cpr.2010.06.004

Coulson S, Woods M, Scott M, Hemment D, Balestrini M (2018) Stop the noise! enhancing meaningfulness in participatory sensing with community level indicators. In: Paper presented at the
Proceedings of the 2018 designing interactive systems conference, Hong Kong, China. https://doi.org/10.1145/3196709.31967 62

Cox J, Oh EY, Simmons B, Lintott C, Masters K, Greenhill A, Holmes K (2015) Defining and measuring success in online citizen science: a case study of zooniverse projects. Comput Sci Eng 17(4):28-41. https://doi.org/10.1109/mcse.2015.65

D’Agostino McGowan L, Stafford JD, Thompson VL, Johnson-Javois B, Goodman MS (2015) Quantitative evaluation of the community research fellows training program. Front Public Health 3:179. https://doi.org/10.3389/fpubh.2015.00179

DITOs Consortium (2016) Doing it together science: terms of reference and evaluation templates. UCL, London

European Citizen Science Association (ECSA) (2020) ECSA's characteristics of citizen science. Retrived 1 May 2020 from https:// ecsa.citizen-science.net/sites/default/files/ecsa_characteristics_ of_citizen_science_-_v1_final.pdf

Evans C, Abrams E, Reitsma R, Roux K, Salmonsen L, Marra P (2005) The Neighborhood Nestwatch Program: participant outcomes of a citizen-science ecological research project. Conserv Biol 19:589-594. https://doi.org/10.1111/j.1523-1739.2005.00s01.x

Fazey I, Bunse L, Msika J, Pinke M, Preedy K, Evely AC, Reed MS (2014) Evaluating knowledge exchange in interdisciplinary and multi-stakeholder research. Glob Environ Chang 25:204-220. https://doi.org/10.1016/j.gloenvcha.2013.12.012

Fraisl D, Campbell J, See L, Wehn U, Wardlaw J, Gold M, Moorthy I, Arias R, Piera J, Oliver JL, Masó J, Penker M, Fritz S (2020) Mapping citizen science contributions to the UN sustainable development goals. Sustain Sci. https://doi.org/10.1007/ s11625-020-00833-7

Friedman AJ (ed) (2008) Framework for evaluating impacts of informal science education projects. Report from a National Science Foundation Workshop. National Science Foundation, Washington, DC

Fritz S, See L, Carlson T, Haklay MM, Oliver JL, Fraisl D, Mondardini R, Brocklehurst M, Shanley LA, Schade S, Wehn U (2019) Citizen science and the United Nations sustainable development goals. Nat Sustain 2(10):922-930. https://doi.org/10.1038/ s41893-019-0390-3

Fung A (2006) Varieties of participation in complex governance. Public Admin Rev 66(s1):66-75. https://doi.org/10.1111/j.1540-6210. 2006.00667.x

Gharesifard M, Wehn U, van der Zaag P (2019a) Context matters: a baseline analysis of contextual realities for two community-based monitoring initiatives of water and environment in Europe and Africa. J Hydrol 579:124144. https://doi.org/10.1016/j.jhydrol. 2019.124144

Gharesifard M, Wehn U, van der Zaag P (2019b) What influences the establishment and functioning of community-based monitoring initiatives of water and environment? A conceptual framework. J Hydrol 579:124033. https://doi.org/10.1016/j.jhydrol.2019. 124033

Gibbons MC, Illangasekare SL, Smith E, Kub J (2016) A community health initiative: evaluation and early lessons learned. Prog Community Health Partnersh Res Educ Action 10(1):89-101. https:// doi.org/10.1353/cpr.2016.0011

Glasgow RE, Emmons KM (2007) How can we increase translation of research into practice? Types of evidence needed. Annu Rev Public Health 28(1):413-433. https://doi.org/10.1146/annurev. publhealth.28.021406.144145

Graef F, Hernandez LEA, König HJ, Uckert G, Mnimbo MT (2018) Systemising gender integration with rural stakeholders' sustainability impact assessments: a case study with three low-input upgrading strategies. Environ Impact Assess Rev 68:81-89. https://doi.org/10.1016/j.eiar.2017.10.004 
Granner M, Sharpe P, Burroughs E, Fields R, Hallenbeck J (2010) Newspaper content analysis in evaluation of a community-based participatory project to increase physical activity. Health Educ Res 25:656-667. https://doi.org/10.1093/her/cyp049

Gresle A-S, Cigarini A, Avila L, Jimeno I, Bagnoli F, Dempere H, Pinazo M-J (2019) An innovative online tool to self-evaluate and compare participatory research projects labelled as science shops or citizen science, pp 59-72

Groulx M, Brisbois MC, Lemieux CJ, Winegardner A, Fishback L (2017) A role for nature-based citizen science in promoting individual and collective climate change action? A systematic review of learning outcomes. Sci Commun 39(1):45-76. https://doi.org/ $10.1177 / 1075547016688324$

Grudens-Schuck N, Sirajuddin Z (2019) Social impacts of citizen science water monitoring programs. J Soil Water Conserv 74(3):49A. https://doi.org/10.2489/jswc.74.3.49A

European Commission (2015) Better Regulation Guidelines, Strasbourg, $\operatorname{SWD}(2015) 111$ final

Guldberg K, Achtypi A, D’Alonzo L, Laskaridou K, Milton D, Molteni P, Wood R (2019) Using the value creation framework to capture knowledge co-creation and pathways to impact in a transnational community of practice in autism education. Int J Res Method Educ. https://doi.org/10.1080/1743727X.2019.1706466

Haklay M (2015) Citizen science and policy: a European perspective. The Wodrow Wilson Center, Commons Lab, Washington

Hassenforder E, Pittock J, Barreteau O, Daniell K, Ferrand N (2016) The MEPPP framework: a framework for monitoring and evaluating participatory planning processes. Environ Manag. https:// doi.org/10.1007/s00267-015-0599-5

Haywood BK (2015) Beyond data points and research contributions: the personal meaning and value associated with public participation in scientific research. Int J Sci Educ. https://doi.org/10.1080/ 21548455.2015.1043659

Haywood B, Besley J (2013) Education, outreach, and inclusive engagement: towards integrated indicators of successful program outcomes in participatory science. Public Underst Sci (Bristol, England). https://doi.org/10.1177/0963662513494560

Hermans F, Haarmann WMF, Dagevos J (2011) Evaluation of stakeholder participation in monitoring regional sustainable development. Reg Environ Change 11:805-815. https://doi.org/10.1007/ s10113-011-0216-y

Hobbs SJ, White PCL (2016) Achieving positive social outcomes through participatory urban wildlife conservation projects. Wildl Res 42(7):607-617. https://doi.org/10.1071/WR14184

Jacobs A, Barnett C, Ponsford R (2010) Three approaches to monitoring: feedback systems, participatory monitoring and evaluation and logical frameworks. IDS Bull 41:36-44. https://doi.org/10. 1111/j.1759-5436.2010.00180.x

Jagosh J, Pluye P, Macaulay A, Salsberg J, Henderson J, Sirett E, Green L (2011) Assessing the outcomes of participatory research: protocol for identifying, selecting, appraising and synthesizing the literature for realist review. Implement Sci 6:24. https://doi.org/ 10.1186/1748-5908-6-24

Jagosh J, Macaulay AC, Pluye P, Salsberg J, Bush PL, Henderson J, Greenhalgh T (2012) Uncovering the benefits of participatory research: implications of a realist review for health research and practice. Millbank Q 9:1-41

Jagosh J, Bush PL, Salsberg J, Macaulay AC, Greenhalgh T, Wong G, Pluye P (2015) A realist evaluation of community-based participatory research: partnership synergy, trust building and related ripple effects. BMC Public Health 15(1):725. https://doi.org/10. 1186/s12889-015-1949-1

Johnson NL, Lilja N, Ashby JA (2003) Measuring the impact of user participation in agricultural and natural resource management research. Agric Syst 78(2):287-306. https://doi.org/10.1016/ S0308-521X(03)00130-6
Jordan RC, Ballard HL, Phillips TB (2012) Key issues and new approaches for evaluating citizen-science learning outcomes. Front Ecol Environ 10(6):307-309. https://doi.org/10.1890/ 110280

Jordan R, Gray S, Sorensen A, Greg N, Mellor D, Hmelo-Silver C, Crall A (2016) Studying citizen science through adaptive management and learning feedbacks as mechanisms for improving conservation. Conserv Biol 30:487-495

Khodyakov D, Stockdale S, Jones A, Mango J, Jones F, Lizaola E (2013) On measuring community participation in research. Health Educ Behav. https://doi.org/10.1177/1090198112459050

Kieslinger B, Schäfer T, Heigl F, Dörler D, Richter R, Bonn A (2017) The challenge of evaluation: an open framework for evaluating citizen science activities. SocArXiv. September 20. https://doi.org/10. 17605/OSF.IO/ENZC9

Kieslinger B, Schäfer T, Heigl F, Dörler D, Richter A, Bonn A (2018) Evaluating citizen science: towards an open framework. Book chapter. In: Citizen science-innovation in open science, Society and Policy. UCL Press, London

Koontz TM, Thomas CW (2012) Measuring the performance of publicprivate partnerships: a systematic method for distinguishing outputs from outcomes. Public Perform Manag Rev 35(4):769-786

Lucero J, Wallerstein N, Duran B, Alegria M, Greene-Moton E, Israel B, White Hat ER (2018) Development of a mixed methods investigation of process and outcomes of community-based participatory research. J Mixed Methods Res 12(1):55-74. https://doi.org/ $10.1177 / 1558689816633309$

Masó J, Fritz S (2019) EuroGEO2019 citizen science roadmap "Lisbon Declaration". Retrived 1 August 2020 from https://zenodo.org/ record/3946506\#. Xw8fI5MzZTY

Masó J, Wehn U (2020) A roadmap for citizen science in GEO-the essence of the Lisbon Declaration. WeObserve policy brief 1

Merenlender A, Crall A, Drill S, Prysby M, Ballard H (2016) Evaluating environmental education, citizen science, and stewardship through naturalist programs. Conserv Biol. https://doi.org/10. 1111/cobi.12737

Moher D, Liberati A, Tetzlaff J, Altman DG, The PG (2009) Preferred reporting items for systematic reviews and meta-analyses: the PRISMA statement. PLoS Med 6(7):e1000097. https://doi.org/ 10.1371/journal.pmed.1000097

National Research Council (2009) Learning science in informal environments: people, places, and pursuits. The National Academies Press, Washington, DC

Naylor PJ, Wharf-Higgins J, Blair L, Green L, O'Connor B (2002) Evaluating the participatory process in a community-based heart health project. Soc Sci Med 55(7):1173-1187. https://doi.org/10. 1016/s0277-9536(01)00247-7

Newman G, Graham J, Crall A, Laituri M (2011) The art and science of multi-scale citizen science support. Eco Inform 6(3-4):217-227

Norris FH, Stevens SP, Pfefferbaum B, Wyche KF, Pfefferbaum RL (2008) Community resilience as a metaphor, theory, set of capacities, and strategy for disaster readiness. Am J Community Psychol 41(1-2):127-150. https://doi.org/10.1007/ s10464-007-9156-6

Oetzel JG, Wallerstein N, Duran B, Sanchez-Youngman S, Nguyen T, Woo K, Alegria M (2018) Impact of participatory health research: a test of the community-based participatory research conceptual model. Biomed Res Int 2018:7281405. https://doi. org/10.1155/2018/7281405

Peter M, Diekötter T, Kremer K (2019) Participant outcomes of biodiversity citizen science projects: a systematic literature review. Sustainability 11:2780. https://doi.org/10.3390/su11102780

Phillips T, Bonney R, Shirk J (2012) What is our impact? Toward a unified framework for evaluating outcomes of citizen science participation. Citizen Sci Public Particip Environ Res 82:95 
Phillips T, Ferguson M, Minarchek M, Porticella N, Bonney R (2014) Evaluating learning outcomes from citizen science. Cornell Lab of Ornithology, Ithaca

Phillips T, Porticella N, Constas M, Bonney R (2018) A framework for articulating and measuring individual learning outcomes from participation in citizen science. Theory Pract Citizen Sci. https:// doi.org/10.5334/cstp. 126

Pocock M, Roy H, August T, Kuria A, Barasa F, Bett J, Trevelyan R (2018) Developing the global potential of citizen science: assessing opportunities that benefit people, society and the environment in East Africa. J Appl Ecol. https://doi.org/10.1111/1365-2664. 13279

Pólvora A, Nascimento S (2017) Impact assessment and recommendations, EUR 29093 EN. Publications Office of the European Union, Luxembourg, ISBN 978-92-79-79336-3. JRC110754. https://doi.org/10.2760/395368

Reed MS, Duncan S, Manners P, Pound D, Armitage L, Frewer L, Frost B (2018) A common standard for the evaluation of public engagement with research. Res All 2(1):143-162. https://doi.org/ 10.18546/RFA.02.1.13

Sandoval JA, Lucero J, Oetzel J, Avila M, Belone L, Mau M, Wallerstein N (2012) Process and outcome constructs for evaluating community-based participatory research projects: a matrix of existing measures. Health Educ Res 27(4):680-690. https://doi. org/10.1093/her/cyr087

Schäfer T, Kieslinger B (2016) Supporting emerging forms of citizen science: a plea for diversity, creativity and social innovation. $\mathrm{J}$ Sci Commun 15(02):Y02

Shirk JL, Ballard HL, Wilderman CC, Phillips T, Wiggins A, Jordan R, Bonney R (2012) Public participation in scientific research: a framework for deliberate design. Ecol Soc. https://doi.org/10. 5751/ES-04705-170229

Silvertown J (2009) A new dawn for citizen science. Trends Ecol Evol 24(9):467-471. https://doi.org/10.1016/j.tree.2009.03.017

Smajgl A, Ward J (2015) Evaluating participatory research: framework, methods and implementation results. J Environ Manag 157:311-319. https://doi.org/10.1016/j.jenvman.2015.04.014

Szilagyi P, Shone L, Dozier A, Newton G, Green T, Bennett N (2014) Evaluating community engagement in an academic medical center. Acad Med. https://doi.org/10.1097/ACM.0000000000 000190

Toomey A, Domroese M (2013) Can citizen science lead to positive conservation attitudes and behaviors? Hum Ecol Rev 20:50-62

Tremblay C (2017) Impact assessment. Community-engaged research (CER) at the University of Victoria, 2009-2015

Tremblay M-C, Martin DH, Macaulay AC, Pluye P (2017) Can we build on social movement theories to develop and improve community-based participatory research? A framework synthesis review. Am J Community Psychol 59(3-4):333-362. https:// doi.org/10.1002/ajcp.12142

Trickett E, Beehler S (2017) Participatory action research and impact: an ecological ripples perspective. Educ Action Res 25:1-16. https://doi.org/10.1080/09650792.2017.1299025

Trimble M, Lázaro M (2014) Evaluation criteria for participatory research: insights from coastal Uruguay. Environ Manag. https:// doi.org/10.1007/s00267-014-0276-0

Van Brussel S, Huyse H (2019) Citizen science on speed? Realising the triple objective of scientific rigour, policy influence and deep citizen engagement in a large-scale citizen science project on ambient air quality in Antwerp. J Environ Plan Manag 62(3):534-551. https://doi.org/10.1080/09640568.2018.1428183

Villaseñor E, Porter-Bolland L, Escobar-Sarria F, Rös M, Chan Dzul AM, Oliveros López S, López Díaz A (2020) Selection of indicators as a tool for negotiating objectives and evaluating targets within participatory monitoring. Sustain Sci 15(4):1051-1065. https://doi.org/10.1007/s11625-020-00795-w

Wehn U, Almomani A (2019) Incentives and barriers for participation in community-based environmental monitoring and information systems: a critical analysis and integration of the literature. Environ Sci Policy 101:341-357. https://doi.org/10.1016/j.envsci. 2019.09.002

Wehn U, Rusca M, Evers J, Lanfranchi V (2015) Participation in flood risk management and the potential of citizen observatories: a governance analysis. Environ Sci Policy 48:225-236. https://doi. org/10.1016/j.envsci.2014.12.017

Wehn U, Pfeiffer E, Gharesifard M, Anema K, Remmers M (2017) Methodology for validation and impact assessment, Ground Truth 2.0 project deliverable D1.10. Delft, the Netherlands

Wehn U, Almomani A, Giller O, Pfeiffer E (2019a) Updated report on incentives and barriers, Ground Truth 2.0 deliverable D1.8, December

Wehn U, Gharesifard M, Anema K, Alfonso L, Mazzoleni M (2019b) Initial validation and socio-economic impacts report (initial submission), Ground Truth 2.0 project deliverable D1.11. Delft, the Netherlands

Wehn U, Gharesifard M, Bilbao A (2020a) D2.2: Report on IA methods adapted to CS. Deliverable report D2.2 of project H2020 MICS (grant agreement No 824711)

Wehn U, Pfeiffer E, Gharesifard M, Alfonso L, Anema K (2020b) Updated validation and socio-economic impacts report, Ground Truth 2.0 project deliverable D1.12. Delft, the Netherlands

Wehn U, Gharesifard M, Ceccaroni L (2020c) D2.3: Impact-assessment methods adapted to citizen science. Deliverable report of project H2020 MICS (grant agreement No 824711)

Whitelaw G, Vaughan H, Craig B, Atkinson D (2003) Establishing the Canadian community monitoring network. Environ Monit Assess 88(1):409-418. https://doi.org/10.1023/a:1025545813057

Wiggins A, Bonney R, Lebuhn G, Parrish JK, Weltzin JF (2018) A science products inventory for citizen-science planning and evaluation. Bioscience 68(6):436-444. https://doi.org/10.1093/biosc ience/biy028

Wohlin C (2014) Guidelines for snowballing in systematic literature studies and a replication in software engineering. In: Proceedings of the 18th international conference on evaluation and assessment in software engineering, pp 1-10. https://doi.org/10.1145/ 2601248.2601268

Woods M, Hemment D, Bui L (2016) Community level indicators, making sense project deliverable D5.4, Dundee, Scotland

Woods M, Ajates R, Gulari N, Burton VJ, van der Velden NK, Hemment D (2019) GROW observatory: mission outcomes. University of Dundee. https://doi.org/10.20933/100001130

Woods M, Coulson S, Ajates R, Hemment D, Balestrini M, Bejtullahu S, Bocconi S, Boerwinkel G, Boonstra M, Boschman D-S, Camprodon G, Diez T, Fazey I, van den Horn C, Ilazi T, JansenDings I, Kresin F, McQuillan D, Nascimento S, Seiz G (2020) Community level indicators tool. University of Dundee. https:// doi.org/10.20933/100001178

Woods M, Ajates R, Gulari N, Coulson S, Consortium GROW (2020) Co-evaluation tool. University of Dundee. https://doi.org/10. 20933/100001180

Publisher's Note Springer Nature remains neutral with regard to jurisdictional claims in published maps and institutional affiliations. 